\title{
Investigating stigma attitudes towards people with mental illness among residents and house officers: an Egyptian study
}

\author{
Abeer M. Eissa ${ }^{1}$, Mahmoud M. Elhabiby ${ }^{1}$, Doha El Serafi ${ }^{1 *} \mathbb{D}$, Hanan H. Elrassas' ${ }^{1}$ Eman M. Shorub ${ }^{1}$ and
} Alaa A. El-Madani

\begin{abstract}
Background: Stigma is a basic component of the negative discrimination that people with mental illness experience every day. It blocks access to facilities that have been created to help people with mental illness. Furthermore, the attitudes held by people with authority (including clinical staff and officers) towards people with mental illness are likely to influence their attitude towards them and hence the experience and treatment outcome of the patients. The aim of this work is to study and compare the attitudes of Egyptian residents of different clinical specialties and house officers towards patients with mental illness. The current study aimed to study the attitudes of Egyptian medical residents and house officers towards patients with mental illness and compare between both groups. This cross-sectional comparative study was designed to assess 150 residents and 201 house officers at Ain Shams University Hospitals by using the Mental IIIness Clinician Attitude Scale version 4 (MICA-4) and newly designed questions related to stigma.

Results: The study revealed that the scores of MICA questionnaire were significantly lower than the cut point for negative attitude in both residents and house officers $(P<0.0001)$. In addition, there was a trend of an increase in MICA scores throughout the three levels of seniority but with no statistically significant difference. Furthermore, there was no statistical significant finding regarding the majority of MICA items or stigma sheet questions across the different specialties.

Conclusion: Stigma is one of the most disabling factors that prevent people with mental illness to live a normal social and occupational life and thus receive a good quality of life and equal chance of medical health care as other non-psychiatric patients.
\end{abstract}

Keywords: Stigma, Mental illness, Attitude, Residents, House officers

\section{Background}

Stigma can be defined as a social process, characterized by exclusion, rejection, or devaluation that results from experience, perception, or reasonable anticipation of an adverse social judgment about a person or group [1].

Stigmatization is a cause for suffering added to illness experience and has been found to lead to social isolation, limited life chances, and delayed help-seeking behavior. The dimensions of stigma identified in mental illness were four dimensions: interpersonal interaction, the

\footnotetext{
* Correspondence: Doha.elserafi@yahoo.com

${ }^{1}$ Faculty of Medicine, Ain Shams University, Cairo, Egypt

Full list of author information is available at the end of the article
}

public image of mental illness, structural discrimination, and access to social roles [2].

In most societies, mental illness carries a substantial stigma. It is considered as an amalgamation of three related problems: a lack of knowledge (ignorance), negative attitudes (prejudice), and exclusion or avoidance behaviors (discrimination). The mentally ill are labeled as different from other people and are viewed negatively by others. Stigmatization can lower a person's selfesteem, contribute to disrupted family relationships, and affect employability [3].

Individuals with mental illness often have to struggle with few problems. First, they have to cope with the 
symptoms of the disease itself. These symptoms can make it difficult for someone with mental illness to work, live independently, or achieve a satisfactory quality of life. Second, the misunderstandings of society about various mental disorders result in stigma. Some persons who manage their mental illness well enough to work still have tremendous difficulties finding a job because employers discriminate against them. Thus, mental illness results not only in difficulties arising from the symptoms of the disease but also in disadvantages through society's reactions. As a further complication, some people with mental illness may accept the common prejudices about mental illness, turn them against themselves, and lose self-confidence [4].

Stigmatizing views about mental illness are not limited to uninformed members of the general public, even well-trained professionals from most health disciplines subscribe to stereotypes about mental illness [3]. It appears that medical students and doctors hold negative attitudes towards people with mental illnesses, including schizophrenia and alcohol and drug abuse. These attitudes towards patients with mental illnesses include dangerousness, unpredictability, being able to communicate with such patients, and that they look different. Negative attitudes were also observed for those with depression, regarding ability to talk to and their ability to "pull themselves" together [5].

One other concern is that doctors still find it difficult to talk to patients with psychiatric disorders. There were also consistently more stigmas on the part of doctors towards patients that are feeling different from themselves, which is an indicator of the doctor's empathy compared with general study. This may lead to unwillingness to approach and interact with people with these conditions either due to fear or that they do not know how to deal with these patients. This in turn may lead to a concern for service provision on general wards by those doctors when looking after patients with concurrent physical and psychiatric illness [6]. Consequently, people with mental illness die prematurely; one reason is that physical healthcare is on average worse than that provided to people without mental health problems. A potential mechanism underlying these disparities is discrimination against people with mental illness by health professionals who share the general public's stigmatizing views towards such people [7].

For mental health service users, stigma must be tackled on many different levels reflecting the varied and complex impact that negative social reactions have on individual's life [8].

The presence of stigma against people with mental illness among medical health personnel carries less quality of medical service, neglect of patient's complaints in medical settings, lack of appropriate doctor-patient relationship, and therefore higher mortality [9]. The aim of work is to study and compare the attitudes of Egyptian residents of different clinical specialties and house officers towards patients with mental illness.

\section{Methods}

A cross-sectional comparative study was conducted to examine the attitude of residents and house officers at Ain Shams University Hospitals towards patients with mental illness.

\section{Participants}

One hundred and fifty non-neuropsychiatric residents and 201 house officers of both genders were selected from a pool of Egyptian residents and house officers who were working in Ain Shams University Hospitals in different clinical specialties during the period from the 10th of November 2013 to the 28th of May 2014.

The residents sample compromised 19 sub-specialties that were grouped into 3 main categories according to the policy of faculty of medicine at Ain Shams University: internal medicines (dermatology, geriatric, cardiology, tropical, chest, oncology and physiotherapy), gynecology and obstetrics, and surgeries (general surgery, neurosurgery, cardiothoracic, ENT, vascular, plastic, urosurgery, orthopedic, ophthalmology and anesthesia).

\section{Clinical questionnaires}

1-Stigma sheet It was designed and reviewed by the research team to obtain a qualitative evaluation of attitude towards mentally ill patients. It was tested with ten residents and house officers to investigate those questions that were understandable and meaningful.

The stigma sheet was composed of ten items in addition to age and gender. It included questions that were collected from literatures, including the following: specialty, degree (years of experience), family history of psychiatric illness, close person with psychiatric illness, and do you think psychiatry is a treatable disease $[5,6,10,11]$.

In addition to other questions, those were consistent to Egyptian and Middle Eastern culture after being approved by the supervisors of the study, including the following: how do you get knowledge about psychiatry; one or more than one source of information (media medical books, undergraduate lectures, from dealing with patients); have you ever treated a psychiatric patient; past history of psychiatric illness; do you see a defect in your knowledge about psychiatric illness: yes/no, if yes, knowledge can be improved by improving undergraduate training, doing a postgraduate training, or both; and how do you see psychiatry as a specialty: medical disease, just talking, or do not believe in it. 


\section{The Mental IIIness Clinician Attitude Scale-4 (MICA-4)}

It is a self-administered scale containing 16 questions, used to assess the attitude of staff across a range of health and social care professions towards psychiatry and psychiatric patients through validated questions about how doctors deal with psychiatric patients and how they see them as a person and if they are ready to communicate with them and accept them in their community; also, it detect how other doctors in different specialties see psychiatry as a specialty. Psychometric validation of the scale was undertaken $[12,13]$.

A person's MICA score is the sum of the scores for the individual items. Items $3,9,10,11,12$, and 16 are scored as follows: strongly agree $=1$, agree $=2$, somewhat agree $=3, \quad$ somewhat disagree $=4, \quad$ disagree $=5, \quad$ and strongly disagree $=6$. All other items $(1,2,4,5,6,7,8$, $13,14,15)$ are reverse scored as follows: strongly agree $=$ 6 , agree $=5$, somewhat agree $=4$, somewhat disagree $=3$, disagree $=2$, and strongly disagree $=1$. The scores for each item are summed to produce a single overall score. A high overall score indicates a more negative (stigmatizing) attitude.

The scale does not have a cutoff point as it is not easy to claim that there is a level above which attitudes are negative. It is a continuous scale, and it is recommended that the mean and standard deviation are to be used. According to the MICA score, those who have higher scores have more negative attitude towards psychiatry. The cutoff point was set at 56 (16 questions with 6 Likert score answers, with the midpoint being 3.5 , this is to mean that 16 questions $\times 3.5$ midpoint $=56$ ).

\section{Procedures}

A pilot study was performed on ten residents and house officers to investigate the designed sheet questions that were understandable and meaningful. The eligible subjects had answered the sheet questions and the Mental illness: clinician attitude scale-4 (MICA-4). The questionnaires were distributed in residents and house officers in all days of the week during day work and shifts. Some residents and house officers refused to do the questionnaire and others did not complete the entire questions, so about 170 questionnaires were overdistributed to reach the sample size calculated according the statistical analysis to reach 100 as a minimal representative sample, and the response rate was about $67 \%$.

\section{Statistical analysis}

The analysis was conducted using SPSS (version 19) for data analysis. Continuous variables such as age were expressed as mean \pm standard deviation, whereas categorical variables such as gender were presented as frequencies (\%). For inferential statistics, the independent $t$ test and one-way ANOVA were used to correlate between scale and categorical variable. The independent $t$ test was used to compare means between two unpaired groups while the one-way ANOVA was used to compare mean score between more than two unpaired groups. For correlation, between two categorical variables, chi-square test was used. Significance level was set at $p<0.05$.

\section{Results}

\section{Demographic characteristics across groups}

The two study groups were age and sex matched with no statistically significant differences. The mean age of resident group was $24.3 \pm 7.2$ years, and the house officer group was $23.2 \pm 4.5$ years. Out of 150 residents, $66.7 \%$ were male and $33.3 \%$ females. Meanwhile, for the 201 house officers, $57 \%$ of respondents were males.

The residents were divided into three groups according to seniority (years of experience) in which $43 \%$ of residents were junior, 32\% sub-senior, and $26.6 \%$ were senior, and there was no statistical significant difference between them $(P=0.07)$. Meanwhile, $46 \%$ of residents were specialized in internal medicine, $54 \%$ specialized in both surgeries, and gynecology and obstetrics.

\section{Comparison of the MICA-4 questions across residents and house officers}

As shown in Table 1, the mean of MICA questionnaires among residents were $51.0 \pm 8.7$ and that among house officers were $(51.28 \pm 8.2)$ that is below the cutoff point (56). Meanwhile, there was no statistical significance difference $(P=0.8)$ between both groups, which means that both groups had positive attitude towards psychiatry and psychiatric patients. However, more than half of house officers were more disagreeing than residents concerning that people with severe mental illness can never recover enough to have good quality of life and to ensure that physical health is assessed for mentally ill. In contrast, $31.7 \%$ house officers were more likely to agree than $20 \%$ residents in attributing physical complaints to mental illness.

As regards the seniority level of residents, there was increasing MICA score throughout the three levels of seniority which means less positive attitude with increasing seniority but with no statistical significant difference between them.

Regarding the score of MICA-4 scale cross resident's specialties, as shown in Table 2, there was no statistically significant difference among different specialty except for three items; first, $55.1 \%$ of internal medicine residents were mostly disagreeing while $71.4 \%$ of gynecology and obstetrics and $63.6 \%$ of surgeries residents were more likely agreeing that patient never recover to have good quality of life. Second, $71.2 \%$ of surgery residents were less likely disagreeing in comparison to their peers concerning attributing physical complaints to mental illness. Lastly, $85.5 \%$ of internal medicine residents were 
Table 1 Comparison of the MICA-4 questions across residents and house officers

\begin{tabular}{|c|c|c|c|c|c|}
\hline \multicolumn{3}{|c|}{16 Questions } & \multirow{2}{*}{$\begin{array}{l}\begin{array}{l}\text { Resident }(n=150) \\
\text { (no/frequency) }\end{array} \\
101(67.8 \%)\end{array}$} & \multirow{2}{*}{$\begin{array}{l}\text { House Officer }(n=201) \\
\text { (no/frequency) }\end{array}$} & \multirow{2}{*}{$\frac{P \text { value }}{0.5}$} \\
\hline$\overline{\mathrm{Q} 1}$ & No additional reading & Agree & & & \\
\hline & & Disagree & $48(32.2 \%)$ & $71(35.5 \%)$ & \\
\hline \multirow[t]{2}{*}{ Q2 } & Patient never recover to have good quality of life & Agree & $83(55.7 \%)$ & $87(43.5 \%)$ & $0.02^{*}$ \\
\hline & & Disagree & $66(44.3 \%)$ & $113(56.5 \%)$ & \\
\hline \multirow[t]{2}{*}{ Q3 } & Working in mental health is respectable & Agree & 146(98\%) & 189(95\%) & 0.1 \\
\hline & & Disagree & $3(2 \%)$ & $10(5 \%)$ & \\
\hline \multirow[t]{2}{*}{ Q4 } & Never admit self-mental illness to friends & Agree & $100(66.7 \%)$ & $128(64 \%)$ & 0.6 \\
\hline & & Disagree & $50(33.3 \%)$ & $72(36 \%)$ & \\
\hline \multirow[t]{2}{*}{ Q5 } & Mentally ill are dangerous & Agree & $112(74.7 \%)$ & $145(72.5 \%)$ & 0.6 \\
\hline & & Disagree & $38(25.3 \%)$ & $55(27.5 \%)$ & \\
\hline \multirow[t]{2}{*}{ Q6 } & Staff know more than family about mental patients & Agree & $122(81.3 \%)$ & $165(82.5 \%)$ & 0.7 \\
\hline & & Disagree & $28(18.7 \%)$ & $35(17.5 \%)$ & \\
\hline \multirow[t]{2}{*}{ Q7 } & Never admit self-mental illness to colleagues & Agree & $112(74.7 \%)$ & 154(77\%) & 0.6 \\
\hline & & Disagree & $38(25.3 \%)$ & $46(23 \%)$ & \\
\hline \multirow[t]{2}{*}{ Q8 } & Staff aren't real health professionals & Agree & $75(50.3 \%)$ & $91(45.7 \%)$ & 0.3 \\
\hline & & Disagree & $74(49.7 \%)$ & $108(54.3 \%)$ & \\
\hline \multirow[t]{2}{*}{ Q9 } & Not following senior for mistreating mentally ill & Agree & 132(88\%) & $164(82 \%)$ & 0.1 \\
\hline & & Disagree & $18(12 \%)$ & $36(18 \%)$ & \\
\hline \multirow[t]{2}{*}{ Q10 } & Comfortably talking to mentally ill & Agree & $60(40 \%)$ & $97(48.5 \%)$ & 0.1 \\
\hline & & Disagree & $90(60 \%)$ & $103(51.5 \%)$ & \\
\hline \multirow[t]{2}{*}{ Q11 } & Ensure that physical health is assessed for mentally ill & Agree & $146(97.3 \%)$ & 183(92\%) & $0.03^{*}$ \\
\hline & & Disagree & $4(2.7 \%)$ & $16(8 \%)$ & \\
\hline \multirow[t]{2}{*}{ Q12 } & Public does not need to be protected from mentally ill & Agree & 49(32.7\%) & $56(28 \%)$ & 0.3 \\
\hline & & Disagree & $101(67.3 \%)$ & $144(72 \%)$ & \\
\hline \multirow[t]{2}{*}{ Q13 } & Attributing physical complaints to mental illness & Agree & $30(20 \%)$ & $63(31.7 \%)$ & $0.01 *$ \\
\hline & & Disagree & $120(80 \%)$ & 136(68.3\%) & \\
\hline \multirow[t]{2}{*}{ Q14 } & General practitioners should not continue an assessment of psychiatric patient & Agree & $86(57.3 \%)$ & $103(51.5 \%)$ & 0.2 \\
\hline & & Disagree & $64(42.7 \%)$ & $97(48.5 \%)$ & \\
\hline \multirow[t]{2}{*}{ Q15 } & Using terms of crazy, nutter, and mad to describe people of mental illness & Agree & 29(19.3\%) & $38(19 \%)$ & 0.9 \\
\hline & & Disagree & $121(80.7 \%)$ & $162(81 \%)$ & \\
\hline \multirow[t]{2}{*}{ Q16 } & Still want to work with a colleague with mental illness) & Agree & $127(84.7 \%)$ & 179(89.5) & 0.1 \\
\hline & & Disagree & 23(15.3\%) & $21(10.5 \%)$ & \\
\hline \multicolumn{3}{|c|}{ MICA total score $($ mean $\pm S D)$} & $51.05 \pm 8.7$ & $51.28 \pm 8.2$ & 0.8 \\
\hline
\end{tabular}

${ }^{*} P \leq 0.05$ showing significant statistical difference

more likely to disagree in comparison to their peers concerning using terms like crazy and nutter to describe the mentally ill.

\section{Comparison of the stigma sheet across residents and house officers}

There was no statistically significant difference among the two groups in all stigma sheet items except $84.5 \%$ of house officer who were less likely to ever treat psychiatric patients than residents (54.4\%), and the statistical difference between them was highly significant $(P=0.00)$ (Table 3).

More than one half of residents and house officers see psychiatry as a treatable disease and a defect in psychiatric knowledge which can be managed by both postgraduate training and improving undergraduate lectures. Furthermore, both groups see psychiatry as a medical disease with biological basis, with no statistically significant difference between them.

Regarding the seniority level, there was a statistically significant difference upon the answer of "defect in 
Table 2 Comparison of the MICA-4 questions across resident's specialties (only significant values are presented)

\begin{tabular}{|c|c|c|c|c|c|c|}
\hline \multicolumn{3}{|c|}{ MICA-4 Questions } & \multirow{2}{*}{$\begin{array}{l}\begin{array}{l}\text { Internal medicines } \\
\text { (no/frequency) }\end{array} \\
31(44.9 \%)\end{array}$} & \multirow{2}{*}{$\begin{array}{l}\text { Surgeries (no/ } \\
\text { frequency) }\end{array}$} & \multirow{2}{*}{$\begin{array}{l}\text { Gynecology and obstetrics } \\
\text { (no/frequency) }\end{array}$} & \multirow{2}{*}{$\begin{array}{l}P \text { value } \\
\mathbf{0 . 0 4 ^ { * }}\end{array}$} \\
\hline Q2 & Patient never recover to have good quality of life & Agree & & & & \\
\hline & & Disagree & $38(55.1 \%)$ & $24(36.4 \%)$ & $4(28.6 \%)$ & \\
\hline \multirow[t]{2}{*}{ Q13 } & Attributing physical complaints to mental illness & Agree & $8(11.6 \%)$ & 19(28.8\%) & $3(20 \%)$ & $0.04^{*}$ \\
\hline & & Disagree & $61(88.4 \%)$ & $47(71.2 \%)$ & $12(80 \%)$ & \\
\hline \multirow[t]{2}{*}{ Q15 } & Using terms of crazy, nutter, and mad to describe & Agree & $9(14.5 \%)$ & $11(22.9 \%)$ & $9(22.5 \%)$ & $0.04^{*}$ \\
\hline & & Disagree & $53(85.5 \%)$ & $37(77.1 \%)$ & $31(77.5 \%)$ & \\
\hline \multicolumn{2}{|c|}{ MICA score } & & $50.1 \pm 8.2$ & $51.7 \pm 9.1$ & $52.05 \pm 8.7$ & 0.4 \\
\hline
\end{tabular}

${ }^{*} P \leq 0.05$ showing significant statistical difference

psychiatric knowledge", 9.7\% of junior resident were more likely to answer "no" than (0\%) sub-senior and (2.5\%) senior. This means that from those who see no defect in knowledge junior residents were the highest between their colleagues.

\section{Comparison between specialties among residents in relation} to stigma sheet

As shown in Table 4, there was a statistically significant difference between the three groups in the two items of the stigma sheet; first, $86.7 \%$ of gynecology and obstetrics residents were likely to have never treated psychiatric patients in comparison to their peers from internal medicine (54.4\%) and surgery specialty (47\%). Second, gynecology and obstetrics residents $(0 \%)$ were less likely to choose doing postgraduate course to manage the defect of their knowledge about psychiatry. Meanwhile, $78.1 \%$ of surgery residents were the most inclined residents towards choosing both (improving undergraduate and doing postgraduate courses) in comparison to their peers.

\section{Discussion}

Mental illness stigma is widely spread in community and reaches not only general population but also health professionals. The impact of these negative attitudes in

Table 3 Comparison of the stigma sheet across residents and house officers

\begin{tabular}{|c|c|c|c|c|}
\hline Stigma sheet items & & $\begin{array}{l}\text { Resident ( } n=150 \text { ) } \\
\text { (no/frequency) }\end{array}$ & $\begin{array}{l}\text { House officer ( } n=201 \text { ) } \\
\text { (no/frequency) }\end{array}$ & $P$ value \\
\hline \multirow[t]{3}{*}{ Source of information } & None & $8(5.3 \%)$ & $10(5 \%)$ & \multirow[t]{3}{*}{0.3} \\
\hline & One source & $87(58 \%)$ & $101(50.5 \%)$ & \\
\hline & More than one & $55(36.7 \%)$ & $89(44.5 \%)$ & \\
\hline Ever treated psychiatric & Yes & $68(45.6 \%)$ & $31(15.5 \%)$ & $0.00^{*}$ \\
\hline Patient & No & $81(54.4 \%)$ & 169(84.5\%) & \\
\hline \multirow[t]{2}{*}{ FH of psychiatric illness } & Yes & $29(19.5 \%)$ & $43(21.5 \%)$ & \multirow[t]{2}{*}{0.6} \\
\hline & No & $120(80.5 \%)$ & 157 (78.5\%) & \\
\hline \multirow[t]{2}{*}{ PH of psychiatric illness } & Yes & $40(26.7 \%)$ & $40(20 \%)$ & \multirow[t]{2}{*}{0.1} \\
\hline & No & $110(73.3 \%)$ & 160(80\%) & \\
\hline \multirow[t]{2}{*}{ Close person with psychiatric illness } & Yes & $59(39.3 \%)$ & $80(40 \%)$ & \multirow[t]{2}{*}{0.9} \\
\hline & No & $91(60.7 \%)$ & $120(60 \%)$ & \\
\hline \multirow[t]{2}{*}{ Psychiatric illness is treatable disease } & Yes & $121(80.7 \%)$ & $166(83.4 \%)$ & \multirow[t]{2}{*}{0.5} \\
\hline & No & $29(19.3 \%)$ & $33(16.6 \%)$ & \\
\hline \multirow[t]{2}{*}{ Defect in psychiatric knowledge } & Yes & 143(95.3\%) & $184(92.5 \%)$ & \multirow[t]{2}{*}{0.2} \\
\hline & No & $7(4.7 \%)$ & $15(7.5 \%)$ & \\
\hline \multirow[t]{3}{*}{ Manage defect of knowledge } & Postgraduate & $17(12.1 \%)$ & $14(7.7 \%)$ & \multirow[t]{3}{*}{0.4} \\
\hline & Undergraduate & $20(14.3 \%)$ & $28(15.4 \%)$ & \\
\hline & Both & 103(73.6\%) & $140(76.9 \%)$ & \\
\hline \multirow[t]{3}{*}{ Perceive psychiatry as specialty } & Medical disease & $132(89.2 \%)$ & $161(82.1 \%)$ & \multirow[t]{3}{*}{0.05} \\
\hline & Just talk & $11(7.4 \%)$ & $31(15.8 \%)$ & \\
\hline & Do not believe & $5(3.4 \%)$ & $4(2 \%)$ & \\
\hline
\end{tabular}


Table 4 Comparison of the stigma sheet items across resident's specialties (Only significant values are presented)

\begin{tabular}{lllll}
\hline Stigma sheet & & $\begin{array}{l}\text { Internal medicines } \\
\text { (no/frequency) }\end{array}$ & $\begin{array}{l}\text { Surgeries } \\
\text { (no/frequency) }\end{array}$ & $\begin{array}{l}\text { Gynecology and obstetrics } \\
\text { (no/frequency) }\end{array}$ \\
\hline Ever treated psychiatric patient & Yes & $31(45.6 \%)$ & $35(53 \%)$ & $2(13.3 \%)$ \\
Manage defect of knowledge & No & $37(54.4 \%)$ & $31(47 \%)$ & $13(86.7 \%)$ \\
& Postgraduate & $12(19.5 \%)$ & $5(7.8 \%)$ & 0 \\
& Undergraduate & $6(9.7 \%)$ & $9(14.1 \%)$ & $5(35.7 \%)$ \\
& Both & $44(71 \%)$ & $50(78.1 \%)$ & $9(64.3 \%)$ \\
\hline
\end{tabular}

${ }^{*} P \leq 0.05$ showing significant statistical difference

mentally ill people is becoming more relevant as mental illness gets more prevalent [14]. Therefore, in the present study, attitudes of Egyptian residents with different categories and specialty and house officers towards psychiatric patients were investigated.

In this study, the attitudes of both residents and house officers' were investigated by using the MICA-4 questionnaire. This is consistent with a study by Robson and colleagues Robson et al. [15] in which they examined the attitudes of mental health nurses towards physical care of people with severe mental illness using the physical health attitude scale for mental health nurses. They revealed a generally positive attitude towards people with severe mental illness [15]. Similarly, Richa \& Naddaf [11] studied the perception of psychiatry and mental disease among Lebanese non-psychiatric doctors and revealed that there was a negative attitude of non-psychiatrist doctors and residents towards mental illness but positive attitudes towards psychiatric treatments, psychiatry, and psychiatrists [11]. Also in line with our results, both McCarthy \& Gijbels [16] and Martin \& Chapman [17] studied the attitude of nurses and medical staffs towards patients who deliberately self-poisoned using the attitude towards self-harm questionnaire. They revealed that doctors have positive attitude towards patients who deliberately self-poisoned and were dealing effectively with patients than nurses $[16,17]$.

In contrast to the present study, Filipeie et al. [10] used anti-stigma questionnaire and revealed stigmatizing attitude towards mentally ill patients. Furthermore, inconsistent with our study, in the UK, they revealed a negative attitude of doctors and medical students with regard psychiatric illness [6]. In Pakistan, a study revealed that medical students and doctors hold negative attitudes towards people with mental illness regarding dangerousness and unpredictability [5]. In addition, in Portugal, Morgado et al. [14] surveyed the prejudicial attitudes of medical students and doctors from psychiatry and internal medicine and they revealed high scores in several stigmatizing attitudes, while psychiatrists and students displayed lower levels of stigmatizing attitudes. Lastly, in the UK, a systematic review study including 74 studies was conducted and revealed that attitudes of general hospital staff especially doctors were largely negative towards people who repeatedly self-harm. Psychiatric staff in community and hospital settings displayed more positive attitudes than general hospital staff; negative attitudes were more common among doctors than nurses, and this was only true for general hospital staff [18]. This difference is related to the use of different questionnaires, different policies in teaching programs among students and residents, and different groups of doctors' specialty and other medical health professionals as we did not study the attitude of psychiatrists in the present study.

As regards the concept of mental diseases treatment, more than one half of residents and house officers see psychiatry as a treatable disease and a defect in psychiatric knowledge which can be managed by both postgraduate training and improving undergraduate lectures. Furthermore, both groups see psychiatry as a medical disease with biological basis. Similar to that concept in the last decade, there has been increasing recognition of significantly poorer health outcomes for people with serious mental illness (SMI) and studies comparing SMI groups to non-SMI identify a higher level of physical health problems [19].

Regarding stigma and years of experience, the present study revealed increasing MICA score throughout the three levels of seniority which means less positive attitude with no statistical significant difference between the three groups. This may be related to the short years of residency (3 years) which is not enough to make a significant difference in attitude. In literature, it is consistently reported by emergency department (ED) staff that they lack adequate education and training to enable them to confidently deliver optimal care to people who have a mental illness [20]. In contrast to our results, in Zagreb, a study showed that senior medical staff has more realistic attitudes towards mental illness than their junior colleagues, this implies that the stigma of mental illness can be reduced by education and experience [10]. In addition, Mukherjee et al. [6] revealed that clinical students showed less stigmatizing attitudes to that of junior doctors and senior doctors [6].

Furthermore, Naeem et al. [5] studied the attitudes among medical students and doctors attending medical colleges in Lahore and found no relationship between 
stigma and years of experience and they attributed that to maybe an indicator of lowered awareness and concern about mental disorder among senior doctors so they did not care to respond in answering the survey form [5].

This difference between the present study and others may be due to the different policies of residency regarding teaching program and longer duration of residency.

Regarding the items of MICA-4 questionnaire, as shown in Table 2, there was no statistically significant difference among different specialty except for certain points; more than half of internal medicine residents were mostly disagreeing that mentally ill patients never recover to have good quality of life and less using terms of crazy to describe mentally ill in comparison to the other two groups. That may be related to their involvement with psychiatrists in treating mentally ill patients through the referral system. In addition, during their first years of residency, as part of their post-graduate curriculums, they are receiving a theoretical psychiatry course and a clinical training in a psychiatric hospital.

Furthermore, as regards the stigma sheet, there was a statistically significant difference between the three groups in two items of the stigma sheet; first, surgery, and gynecology and obstetrics residents were likely to have never treated psychiatric patients and less likely to choose doing postgraduate course to manage the defect of their knowledge about psychiatry in comparison to their peers of internal medicine. This may be due to their concepts that mentally ill patients never recover to have good a quality of life and disagreement to attribute physical complaints to mental illness. This was inconsistent with a study in London by Mukherjee et al. [6] which found that medical and surgical specialties have no statistically significant difference found, and all showed a similar pattern of negative attitudes [6]. This difference between our study and others may be due to different culture as many psychiatric patients in our culture do not admit their mental illness to doctors of other specialty for fear not to be well treated.

It is approved that there is a gap in the study of resident's beliefs towards the mental health, so there is a need for theoretical and practice frameworks towards the physical and mental health needs, within which, mental health professionals can holistically plan and deliver interventions to improve outcomes. In addition, put team work strategies between different specialties [21].

To the best of our knowledge, the current work is the first Egyptian study exploring the attitude of residents with different experience years and specialty and house officers towards psychiatric patients, also elaborating how this attitude influences the medical services that physicians give to these patients and how then it will affect the patient's quality of life and life expectancy. But the findings of this study should be interpreted with caution, due to several limitations. Firstly, the findings are based on a self-report survey which may be subjected to over-reporting or underreporting by the respondents. Secondly, the study was limited on residents and house officers of university hospitals not including those in other hospitals of the ministry of health or other medical health professionals. Finally, this study is cross-sectional in nature and, as such, does not permit inferring causal relationships among the variables, and the results could roughly be generalized. To that end, more research is needed to elaborate attitudes of nurses, students, public, family, and psychiatrists towards psychiatric patients.

\section{Conclusion}

Stigma is one of the most disabling factors that prevent people with mental illness to live a normal social and occupational life and thus receiving a good quality of life and equal chance of medical health care as other non-psychiatric patients. In our study, we concluded that both residents of different specialties and house officers have positive attitude towards psychiatry and psychiatric patients.

\section{Acknowledgements \\ We as authors thank all the colleagues participating in this study.}

Ethics committee reference number

Ain Shams University, Faculty of Medicine, Research Ethics Committee (REC) FWA 00006444.

\section{Authors' contributions}

$\mathrm{MH}$ was a major contributor in guiding, revising, analyzing, and interpreting the collected data and the manuscript. DS analyzed and interpreted the patients' data concerning the results of the tests done and was a major contributor in writing the main script. ES was a major contributor in writing and data collection for updated references. HR was a major contributor in collecting the sample performing the test. All authors read and approved the final manuscript.

Funding

Not applicable.

Availability of data and materials

All data generated or analyzed during this study are included in this published article.

\section{Ethics approval and consent to participate}

This study has been approved by the Ethics and Research Committee of the Psychiatric Institute at Ain Shams University. Written informed consent from residents and house officers was received prior to data collection.

Consent for publication

Not applicable.

Competing interests

The authors declare that they have no competing interests.

Author details

${ }^{1}$ Faculty of Medicine, Ain Shams University, Cairo, Egypt. ${ }^{2}$ El Abbasia Hospital, Cairo, Egypt.

Received: 12 December 2019 Accepted: 26 January 2020

Published online: 10 April 2020

References

1. Scambler G (2009) Health related stigma. Sociol Health Illness 31:441-445 
2. Schulze B, Matthias C et al (2003) Subjective experiences of stigma. Soc Sci Med 56:299-312

3. Picco L, Chang S et al (2019) Associative stigma among mental health professionals in Singapore: a cross sectional study. BMJ Open 9:e028179. https://doi.org/10.1136/bmjopen-2018-028179

4. Rusch N, Angermeyer M, Corrigan P (2005) Mental illness stigma: concepts, consequences and initiative to reduce stigma. Eur Psychiatry 20:529-539

5. Naeem F, Ayub M et al (2006) Attitude of the university students and teachers towards mentally ill, in Lahore, Pakistan. J Ayub Med Coll Abbottabad 18:3

6. Mukherjee R, Fialho A et al (2002) The stigmatization of psychiatric illness: the attitudes of medical students and doctors in a London teaching hospital. Psychiatr Bull 26:178-181

7. Friedrich B, Lacko S et al (2013) Anti-stigma training for medical students: the education not discrimination project. Br J Psychiatry 202:89-94

8. Pinfold V, Byrne P et al (2005) Challenging stigma and discrimination in communities: a focus group study identifying UK mental health service users' main campaign priorities. Int J Psychiatry 51:128-138

9. Szeto A, Dobson K (2010) Reducing the stigma of mental disorders at work: a review of current workplace anti-stigma intervention programs. Appl Prev Psychol 14:41-56

10. Filipeie I, Pavieie D, Filipeie A et al (2003) Attitudes of medical staff towards the psychiatric label schizophrenic patient tested by an anti-stigma questionnaire. Coll Antropol 27:301-307

11. Richa S \& Naddaf M (2009) Perception of psychiatry and mental disease among Lebanese non psychiatric doctors. Eur Psychiatry 24:5965

12. Kassam A, Glozier N, Leese M et al (2010) Development and responsiveness of a scale to measure clinicians attitudes to people with mental illness (medical student version). Acta Psychiatr Scand 122(2):153-161

13. Gabbidon J, Clement S, Nieuwenhuizen AV et al (2013) Mental illness: clinicians' attitudes (MICA) scale. Psychometric properties of a version for students and professionals in any healthcare discipline. Psychiatry Res 205 $81-87$

14. Morgado P, Oliveira A, Machado D et al (2013) Stigmatizing attitudes towards mental ill patients among medical students and professionals. Eur Psychiatry 28:1

15. Robson D, Haddad M, Gray R et al (2013) Mental health nursing and physical health care: a cross-sectional study of nurses' attitudes, practice, and perceived training needs for the physical health care of people with severe mental illness. Int J Ment Health Nurs 22:409-417

16. McCarthy L \& Gijbels H (2010) An examination of emergency department nurse's attitudes towards deliberate self-harm an Irish teaching hospital. Int Emerg Nurs 18:29-35

17. Martin C \& Chapman R (2014) A mixed method study to determine the attitude of Australian emergency health professionals towards patients who present with deliberate self-poisoning. Int Emerg Nurs 22:98-104

18. Saunders $\mathrm{K}$, Hawton $\mathrm{K}$ et al (2012) Attitudes and knowledge of clinical staff regarding people who self-harm: a systematic review. J Affect Disord 139: 205-216

19. Seeman N, Tang S, Brown AD, Ing A (2016) World survey of mental illness stigma. J Affect Disord 190(2016):115-121

20. Marynowski-Traczyk D, Moxham L, Broadbent M (2013) A critical discussion of the concept of recovery for mental health consumers in the emergency department. Australas Emerg Nurs J 16:96-102

21. Zieger A, Mungee A, Schomerus G et al (2017) Attitude toward psychiatrists and psychiatric medication: a survey from five metropolitan cities in India. Indian J Psychiatry 59:341-346

\section{Publisher's Note}

Springer Nature remains neutral with regard to jurisdictional claims in published maps and institutional affiliations.

\section{Submit your manuscript to a SpringerOpen ${ }^{\circ}$ journal and benefit from:}

- Convenient online submission

- Rigorous peer review

- Open access: articles freely available online

- High visibility within the field

- Retaining the copyright to your article

Submit your next manuscript at $\boldsymbol{\nabla}$ springeropen.com 